\title{
Attrition Rupture of Ulnar Nerve in an Elbow of a Patient with Rheumatoid Arthritis
}

KENSUKE OCHI, MD, PhD, Assistant Professor, Department of Orthopedic Surgery, Institute of Rheumatology, Tokyo Women's Medical University; Japan Department of Orthopedic Surgery, Keio University School of Medicine; KATSUNORI IKARI, MD, PhD, Associate Professor; SHIGEKI MOMOHARA, MD, PhD, Professor, Department of Orthopedic Surgery, Institute of Rheumatology, Tokyo Women's Medical University, Shinjuku, Tokyo, Japan. Supported in part by grants-in-aid for scientific research from the Japanese Society for Surgery of the Hand, the Japan Society for the Promotion of Science, the Nakatomi Foundation, and the Japan Orthopedics and Traumatology Foundation Inc. No. 277 to K.O. Address correspondence to Dr. K. Ochi, Department of Orthopedic Surgery, Keio University School of Medicine, 35 Shinanomachi, Shinjuku, Tokyo, 160-8582, Japan. E-mail: ochi@1998.jukuin.keio.ac.jp. J Rheumatol 2014;41:2085; doi:10.3899/jrheum.140555

Ulnar nerve neuropathy at the elbow is often seen in patients with rheumatoid arthritis (RA). Diagnosis of this neuropathy in patients with RA is often delayed, because palsy of this neuropathy is sometimes difficult to distinguish from functional impairment caused by RA in the hand ${ }^{1}$.

A 68-year-old woman with a 47-year history of RA was referred to our clinic with ulnar nerve palsy around her elbow. She experienced numbness and sensory disturbance in the ulnar nerve region for more than 2 years, with severe pain on elbow flexion. A nerve conduction study indicated a delay in the ulnar nerve $(10.8 \mathrm{~m} / \mathrm{s})$, and her elbow joint was severely damaged and unstable with cubitus valgus (Figure 1A). As she declined to undergo total elbow arthroplasty, anterior subcutaneous transposition was performed on her right ulnar nerve. The medial articular capsule was perforated, and the ulnar nerve was directly exposed up to the joint (Figure 1B). Her ulnar nerve was attrited and partially ruptured; two-thirds of the diameter of the ulnar nerve was defected for $2 \mathrm{~cm}$ in length (Figure 1C). This nerve injury seemed to be an attrition rupture as a result of friction between the nerve and the edge of the damaged joint. The numbness improved postoperatively.

Management of RA has significantly improved in this decade $^{2,3}$. Although attrition rupture of the ulnar nerve was a very rare condition even when the management was poor ${ }^{4,5}$, our case suggested that this condition could still be possible today, especially if the elbow is damaged with severe cubitus valgus. It is important to consider anterior transposition of the ulnar nerve with or without total elbow arthroplasty in patients with RA with this neuropathy.

\section{ACKNOWLEDGMENT}

We thank all the members of the Institute of Rheumatology, Tokyo Women's Medical University, and of the Department of Orthopedic Surgery, Keio University School of Medicine for their support.

\section{REFERENCES}

1. Nakano KK. The entrapment neuropathies of rheumatoid arthritis. Orthop Clin North Am 1975;6:837-60.

2. Lipsky PE, van der Heijde DM, St. Clair EW, Furst DE, Breedveld FC, Kalden JR, et al. Infliximab and methotrexate in the treatment of rheumatoid arthritis. Anti-tumor necrosis factor trial in rheumatoid arthritis with concomitant therapy study group. N Engl J Med 2000;343:1594-602.

3. Yamanaka H, Seto Y, Tanaka E, Furuya T, Nakajima A, Ikari K, et al. Management of rheumatoid arthritis: the 2012 perspective. Mod Rheumatol 2012;23:1-7.

4. Moore JR, Weiland AJ. Bilateral attritional rupture of the ulnar nerve at the elbow. J Hand Surg Am 1980;5:358-60.

5. Kalaci A, Aslan B, Yanat AN. Spontaneous rupture of ulnar nerve due to neglected cubital tunnel syndrome associated with rheumatoid arthritis. J Clin Rheumatol 2007;13:217-8.
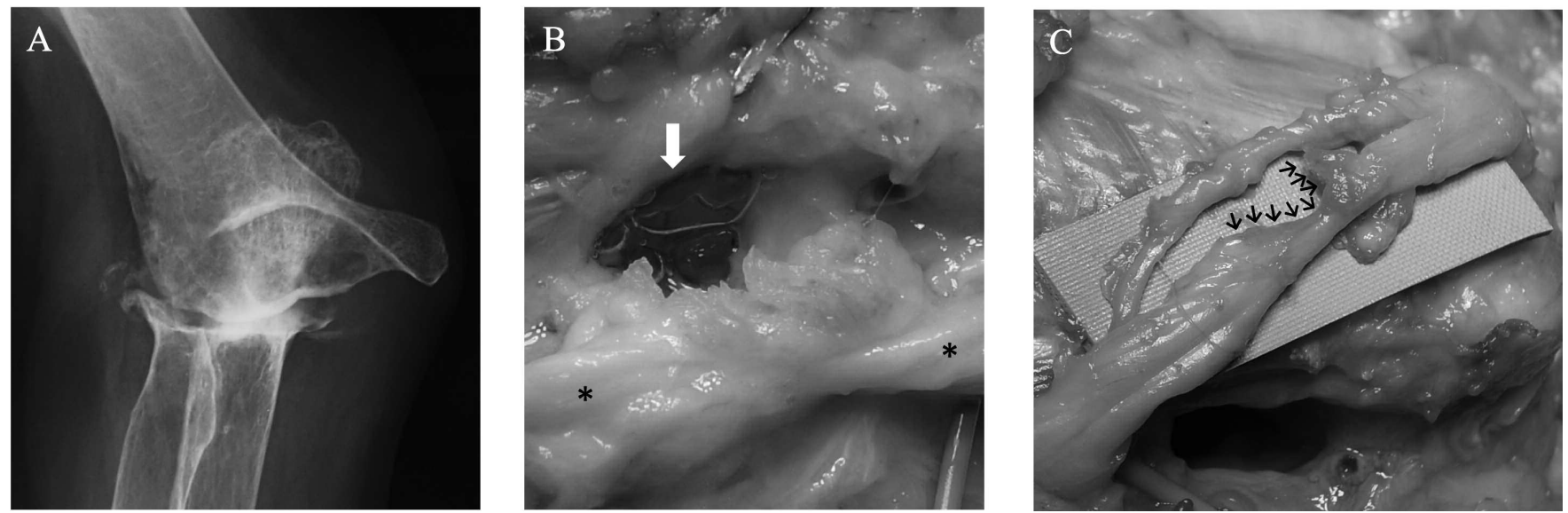

Figure 1. A. Radiograph of the patient's severely damaged, unstable elbow joint. B. Patient's medial articular capsule was perforated (arrow), and the ulnar nerve (star) was directly exposed up to the joint. C. Attrited and partially ruptured ulnar nerve; two-thirds of the diameter of the ulnar nerve was defected for $2 \mathrm{~cm}$ in length (arrows).

Personal non-commercial use only. The Journal of Rheumatology Copyright (c) 2014. All rights reserved. 